\title{
The Long-Term Health and Human Capital Consequences of Adverse Childhood Experiences in the Birth to Thirty Cohort: Single, Cumulative, and Clustered Adversity
}

\author{
Sara N. Naicker ${ }^{1, * \mathbb{D}}$, Marilyn N. Ahun ${ }^{2,3}$, Sahba Besharati ${ }^{4,5} \mathbb{D}$, Shane A. Norris ${ }^{1,6,7}$ (D), Massimiliano Orri ${ }^{8}$ \\ and Linda M. Richter ${ }^{1}$ (D)
}

check for updates

Citation: Naicker, S.N.; Ahun, M.N.; Besharati, S.; Norris, S.A.; Orri, M.; Richter, L.M. The Long-Term Health and Human Capital Consequences of Adverse Childhood Experiences in the Birth to Thirty Cohort: Single, Cumulative, and Clustered Adversity. Int. J. Environ. Res. Public Health 2022 19, 1799. https://doi.org/10.3390/ ijerph19031799

Academic Editors: Alexander Testa, Dylan B. Jackson and Michael G. Vaughn

Received: 7 January 2022

Accepted: 3 February 2022

Published: 5 February 2022

Publisher's Note: MDPI stays neutral with regard to jurisdictional claims in published maps and institutional affiliations.

Copyright: (C) 2022 by the authors. Licensee MDPI, Basel, Switzerland. This article is an open access article distributed under the terms and conditions of the Creative Commons Attribution (CC BY) license (https:// creativecommons.org/licenses/by/ $4.0 /)$.
1 DSI-NRF Centre of Excellence in Human Development, University of the Witwatersrand, Johannesburg 2050, South Africa; shane.norris@wits.ac.za (S.A.N.); linda.richter@wits.ac.za (L.M.R.)

2 Department of Global Health and Population, Harvard T.H. Chan School of Public Health, Boston, MA 02115, USA; mahun@hsph.harvard.edu

3 School of Public Health, Université de Montréal, Montreal, QC H3C 3J7, Canada

4 Department of Psychology, School of Human and Community Development, University of the Witwatersrand, Johannesburg 2050, South Africa; sahba.besharati@wits.ac.za

5 CIFAR Azrieli Global Scholars Program, CIFAR, Toronto, ON M5G 1M1, Canada

6 SAMRC Developmental Pathways for Health Research Unit, University of the Witwatersrand, Johannesburg 2050, South Africa

7 Hubert Department of Global Health, Rollins School of Public Health, Emory University, Atlanta, GA 30322, USA

8 McGill Group for Suicide Studies, Department of Psychiatry, Douglas Mental Health University Institute, McGill University, Montreal, QC H3A 0G4, Canada; massimiliano.orri@mcgill.ca

* Correspondence: sara.naicker@wits.ac.za

\begin{abstract}
Human capital — that is the cumulative abilities, education, social skills, and mental and physical health one possesses-is increasingly recognized as key to the reduction of inequality in societies. Adverse childhood experiences have been linked to a range of human capital indicators, with the majority of research in high-income, western settings. This study aims to examine the link between adverse childhood experiences and adult human capital in a South African birth cohort and to test whether associations differ by measurement of adversity. Secondary analysis of data from the Birth to Thirty study was undertaken. Exposure data on adversity was collected prospectively throughout childhood and retrospectively at age 22. Human capital outcomes were collected at age 28. Adversity was measured as single adverse experiences, cumulative adversity, and clustered adversity. All three measurements of adversity were linked to poor human capital outcomes, with risk for poor human capital increasing with the accumulation of adversity. Adversity was clustered by quantity (low versus high) and type (household dysfunction versus abuse). Adversity in childhood was linked to a broad range of negative outcomes in young adulthood regardless of how it was measured. Nevertheless, issues of measurement are important to understand the risk mechanisms that underlie the association between adversity and poor human capital.
\end{abstract}

Keywords: adverse childhood experiences; ACEs; human capital; birth cohort; clustered adversity

\section{Introduction}

Human capital is collectively the knowledge, skills, and health inputs accumulated across the lifespan that enables individuals to realize their full potential and contribute to the economic productivity of a society. It is manifest through a range of constructs, including educational attainment, physical and mental health, and social outcomes. It is well documented that human capital trajectories vary greatly within communities [1] and that one's early experiences account for a substantial portion of the variation in adult human capital outcomes [2-4]. Another construct linked to economic productivity is adverse 
childhood experiences (ACEs), which is related to poorer health and social outcomes-or human capital-across the life course [5-7]. Early adversity in general, including child maltreatment, has long been established as detrimental for health and wellbeing [8,9]. Furthermore, the concept of ACEs-a quantifiable index of exposure to a range of adverse experiences, has in recent years been linked to a range of negative outcomes. The original ACE study found significant associations between ACEs and risk for alcoholism, drug abuse, smoking, risky sexual behavior, obesity, depression, suicide attempt, heart disease, cancer, chronic lung disease, liver disease, and skeletal fractures [10]. Following this seminal study, publications linking ACEs to one or more outcome grew exponentially [11] and systematic reviews and meta-analyses provided valuable overviews. One meta-analysis reviewed 37 studies and described links between greater exposure to ACEs and physical inactivity, overweight, obesity, diabetes, smoking, heavy alcohol use, sexual risk behavior, cancer, heart disease, respiratory disease, and mental ill health [7]. A second meta-analysis assessed 96 studies in which ACEs were examined against health and wellbeing outcomes. The study's findings mirrored those of the previous meta-analysis, linking ACEs to a range of psychosocial, behavioral, and physical health outcomes [6]. Finally, a third meta-analysis on studies from Europe and North America not only connected ACEs to risk factors for ill health, but estimated the associated annual financial costs attributable to ACEs to be $\$ 581$ billion in Europe and \$748 billion in North America [12]. Identifying the specific ACEs or combinations of ACEs that are strongly linked to adult human capital outcomes may help elucidate the mechanisms of these associations and aid in developing targeted interventions to reduce the risk of poor human capital outcomes.

However, the measurement of ACEs has important limitations. Studies typically rely on cumulative risk scores [13] or individual adversities measured through retrospective self-reports [14]. Evidence describes the relationship between ACEs and social and health problems as one that predicts the risk to increase in a strong and graded manner as the number and severity of ACEs increase $[15,16]$. Hence, a single adversity approach ignores the high probability that adversities co-occur and have an exponential impact. On the other hand, cumulative risk scores assume equal weighting of adversities while a number of studies have shown specific ACEs to be more deleterious than others [17-19]. Although there are currently no guidelines on the ACEs scoring in the available literature, some studies point to the 'four or more' cut-off functioning as a threshold level, with noticeable deviations in a range of outcomes at that mark [7]. As an alternative to both of these approaches, analyses of the patterning of ACEs recognize that the clustering and qualitative differences in combinations of ACEs are important for health and social outcomes and are linked to different consequences [20,21].

Another important limitation in ACEs research is the reliance on retrospective reports [6]. Previous research in longitudinal birth cohorts has demonstrated that prospective and retrospective reports of ACEs show poor agreement [22,23], similar to findings in this cohort [24], and are differentially linked to outcomes [17,23]. Meta-analysis findings conclude that prospective and retrospective measures of ACEs largely identify two different sets of individuals, cautioning that the measures should not be used interchangeably to study pathways of risk and outcomes. It is therefore important to compare findings based on prospective and retrospective measures in the same individuals.

Conceptually, frameworks such as the ACEs Pyramid-emanating from the ACEs study-attempt to explain the ways in which early adversity disrupts biological and psychological processes through interactions between genes and the environment [25]. The bio-developmental framework posits that early adversity precedes physiological maladaptations and disruptions due to either cumulative exposure or biological embedding during sensitive periods, leading to a range of poor health and wellbeing outcomes [26]. The ACEs Pyramid follows this logic but recognizes that exposure to ACEs is somewhat predetermined by social conditions and historical trauma in societies. ACEs then go on to disrupt neurodevelopment, giving rise to socio-emotional and cognitive impairments linked to 
the adoption of health risk behaviors that increase vulnerability to disease, disability, and social problems [10].

The objectives of this study are therefore to (a) examine the associations between ACEs and adult human capital, and (b) explore how the measurement of ACEs may vary in relation to these human capital outcomes. Prior research, including studies using this cohort, have highlighted sex differences in the prevalence of ACEs and their associations with outcomes [17,24,27-30]. The patterning of ACEs and their links to human capital outcomes will be disaggregated by sex throughout this analysis. To our knowledge, no study to date has investigated the relationship between ACEs and adult human capital outcomes, using these unique measurement methods, in low-middle income countries (LMICs).

\section{Materials and Methods}

\subsection{Study Design and Participants}

The Birth to Thirty study (Bt30, previously known as Birth to Twenty Plus) is a South African birth cohort of all singleton children born to mothers who were residents of Soweto, Johannesburg in a 7-week period of enrolment in 1990 [31]. The study is the largest and longest running birth cohort on the African continent, with an initial recruitment of 3273 participants, including their primary caregivers and subsequently a third generation born to the original cohort. The study has routinely followed participants through 23 data collection points over its 30-year lifespan, assessing growth, health, education, and wellbeing domains. At each of the data collection waves, well-trained field staff conducted face-to-face interviews with each participant for all interviewer-administered questionnaires and were available to assist with all self-administered questionnaires. A set of core questionnaires were routinely administered at each wave, assessing socio-demographics, household information, community and school environment, health and nutrition, risk behaviors, and more. The exposures and outcomes used in this study were pulled from selected sections in these questionnaires. Detailed descriptions of the cohort methods and sample have been published elsewhere [31-34]. For this study, data on 1436 participants included in the last data collection wave at age 28 were used. Ethics clearance was obtained from the Witwatersrand University Committee for Research on Human Subjects and written consent was obtained from all participants.

\subsection{Exposures}

ACEs in this study are defined as physical abuse, sexual abuse, emotional abuse or neglect, household dysfunction in the form of experience of divorce or parental separation, child separation, exposure to intimate partner violence (IPV), experience of living with a chronically ill or disabled individual or an individual with substance abuse problems, parental death, household legal trouble, and chronic household unemployment. ACEs were taken from a 'life events' section in the routine Bt30 questionnaire, which probed for recent major life events or changes (Supplementary Table S1). Retrospective reports of individual ACEs were created from a single report in the 22-23-year data collection wave. Prospective reports of individual ACEs were composed across the first 18 years of available data from caregiver reports (children aged 0-7 years old) and self-reported by the Bt30 participant thereafter.

\subsection{Outcomes}

Human capital outcomes were measured at age 28 and include both health and social measures conceptualized in a previous study [2].

\subsubsection{Education and Employment}

Education refers to incomplete secondary schooling. Participants reported their highest school grade attained, dichotomized into complete (coded 0 ) or incomplete (1) secondary education. For the employment outcome, participations reported whether they were formally employed (i.e., had a work contract), (coded ' 0 ') vs. not formally employed (' 1 '). 
Both education and employment were single questions under their respective sub-sections in the routine $\mathrm{Bt} 30$ questionnaire at age 28.

\subsubsection{Welfare Receipt}

Welfare receipt refers to a government cash transfer available to primary caregivers of children who qualify through an income means test. Welfare receipt in the form of a Child Support Grant (yes, coded '1', vs. no, '0') was recorded from administrative data supplied by the South African Social Security Agency. A single variable indicating whether or not the individual is receiving the grant was linked to the Bt30 data. Participants consented to the linking of this data through identity numbers.

\subsubsection{Mental Health}

Mental health was conceptualized as psychological distress and assessed using the World Health Organization's Self Reporting Questionnaire. Items include 20 questions assessing symptoms experienced during the past month, such as "Do you feel nervous, tense or worried?" and "Do you sleep badly?", coded in a binary manner and summed to obtain a total psychological distress score (alpha $=0.93$ ). Participants in the top $20 \%$ of symptoms score were considered as having high psychological distress.

\subsubsection{Social Isolation}

Social isolation was assessed using 8 items based on the Inventory of Socially Supportive Behaviors, such as "How often you had someone who would listen to you when you needed to talk", "Had someone you trust to talk with about your problems". Items were answered on a 5-point scale from never to always, and then summed. Scores were dichotomized to identify participants who reported high levels of social isolation (scoring at the bottom decile of the distribution was coded ' 1 ', versus those reporting lower levels, coded ' 0 ').

\subsubsection{Substance Abuse and Criminality}

Substance abuse was derived from either reporting alcohol use more than 2-3 times a week and/or current use of non-medical drugs (including marijuana), scored as yes ('1') or no $\left({ }^{\prime} 0^{\prime}\right)$. Criminality was assessed by asking participants whether, in the last year, they had been arrested, detained, jailed, or committed a crime without being caught, for example, stolen a car/motorbike, stolen in a shop or from a person, sold drugs or stolen goods, set property on fire or damaged/destroyed property, assaulted someone, or forced someone to have sex. A positive answer to any of the questions was coded ' 1 ' versus ' 0 '. These questions were taken from a section on 'delinquency' in the Bt30 routine questionnaire.

\subsubsection{HIV Infection}

HIV status was assessed with a single question asking, "Have you ever tested positive for HIV?', coded ' 1 ' if yes and ' 0 ' if no.

\subsection{Covariates}

Covariates were included in this study based on their significance in the literature to multiple health and wellbeing outcomes [35,36], including in prior work on this cohort [2,17]. The covariates include sex; socio-economic status at participant birth, age 12, and age 22, measured as wealth quintiles derived from a list of assets (e.g., television, fridge, car, phone); maternal age at birth sorted into 4 age categories based on the distribution of maternal age (15-18, 19-24, 25-34, 35-46), and continuous measures of maternal and paternal years of schooling. 


\subsection{Statistical Analysis \\ Measuring ACEs}

Single ACEs were included in the analyses as individual binary variables. Each ACE was coded ' 0 ' for a negative response and ' 1 ' for a positive response.

To measure the effects of cumulative adversity, the individual binary ACEs were transformed into a categorical score with 5 levels for each participant, as follows: $0=$ 'no reported $\mathrm{ACEs}$ ', 1 = 'one reported $\mathrm{ACE}^{\prime}, 2$ = 'two reported $\mathrm{ACEs}$ ', 3 = 'three reported $\mathrm{ACEs}$ ' and $4+=$ 'four or more reported ACEs', following convention in the literature and allowing for comparability with other studies. The Bt30 sample has limited variability in its socio-economic status, similar low variability in the distribution of ACEs, and high prevalence of ACEs, given that the site of the study (i.e., Soweto, Johannesburg) is a previously socio-economically disadvantaged and low-income area. Most studies assessing either prospective or retrospective ACEs are based in high-income countries, often with populations with more heterogeneity in the distribution of ACEs [22]. To maximize withincell counts and meaningfully analyze the data, cumulative ACEs were also categorized in a binary fashion as ' 0 ' = 'less than six' and ' 1 ' $=$ 'six or more' reported ACEs. The 'six or more ACEs' cut-off was preferred over the conventional cut-off of ' 4 or more ACEs' as this represents the mean ACE score for the Bt30 sample and takes into account the higher prevalence of ACEs in the sample.

Clusters of ACEs were derived using latent class analysis (LCA), a mixture model technique that identifies groups of individuals (i.e., latent classes) on the bases of similarities in their pattern of co-occurrence of ACEs exposure. LCA was separately applied to the prospective and the retrospective reports. Several models were estimated with 2 to 6 latent classes and compared using the Bayesian Information Criteria (BIC, used as primary index), Akaike's Information Criteria (AIC), and sample size-adjusted BIC (SSABIC). Lower values of the BIC, AIC, and SSABIC indicate a better fitting model. Entropy was also used to assess the distinction between classes, where values closer to 1 indicate good distinction (Supplementary Table S2). Once the best model was identified, participants were assigned to their most likely class, creating a categorical cluster variable. LCA was performed with Mplus version 8, with missing data on ACEs variables handled using Full Information Maximum Likelihood.

Associations between the 3 methods of measuring ACEs-single, cumulative, and clustered-and human capital outcomes-were examined using logistic regression. Two sets of models were fitted for each ACE measurement for both retrospective and prospective reports of ACEs: (i) a crude, unadjusted model (Supplementary Tables S3 and S4), followed by (ii) models adjusted for all covariates (Supplementary Tables S5 and S6). Sex was included as a covariate in all models but separate analysis by sex, excluding the variable at the covariate level, was conducted and is available in Supplementary Tables S7 and S8. To handle missing data on the covariates, we used multiple imputation by chained equations, so that models were estimated across 10 datasets and then pooled. All data management, multiple imputation, and regression analyses were conducted in Stata version 15.1. Data missingness for each of the ACEs, covariates, and outcomes is detailed in Table 1.

Table 1. Description of the study sample $(n=1436)$.

\begin{tabular}{lcccc}
\hline Variable & Male & Female & Total & Missing \\
\hline Exposures & & & & \\
Single Prospective ACEs & & & & \\
Physical abuse & $400(58.57)$ & $381(50.73)$ & $781(54.65)$ & $2(0.14)$ \\
Sexual abuse & $267(39.09)$ & $278(37.17)$ & $545(38.13)$ & $5(0.35)$ \\
Emotional abuse & $245(35.98)$ & $265(35.43)$ & $510(35.71)$ & $7(0.49)$ \\
Child separation & $92(14.00)$ & $120(16.28)$ & $212(15.14)$ & $42(2.92)$ \\
Parental divorce & $332(49.63)$ & $392(52.55)$ & $724(51.09)$ & $21(1.46)$ \\
Parental death & $160(23.74)$ & $152(20.27)$ & $312(22.01)$ & $12(0.84)$ \\
Household death & $416(64.63)$ & $463(61.49)$ & $879(63.06)$ & $8(0.56)$ \\
\hline
\end{tabular}


Table 1. Cont.

\begin{tabular}{|c|c|c|c|c|}
\hline Variable & Male & Female & Total & Missing \\
\hline Household substance abuse & $305(46.42)$ & $355(48.30)$ & $660(47.36)$ & $44(3.06)$ \\
\hline Household illness/disability & $413(62.86)$ & $460(62.42)$ & $873(62.64)$ & $42(2.92)$ \\
\hline Household legal trouble & $292(43.20)$ & $228(30.32)$ & $520(36.76)$ & $8(0.56)$ \\
\hline Chronic unemployment & $567(86.30)$ & $634(86.02)$ & $1201(86.16)$ & $42(2.92)$ \\
\hline Exposure to IPV & $372(54.55)$ & $285(37.95)$ & $657(46.25)$ & $3(0.21)$ \\
\hline Exposure to violence & $530(77.71)$ & $474(63.03)$ & $1004(70.37)$ & $2(0.14)$ \\
\hline Prospective ACE category & & & & $0(0.0)$ \\
\hline 0 ACEs & $3(0.44)$ & $5(0.66)$ & $8(0.55)$ & \\
\hline $1 \mathrm{ACE}$ & $12(1.76)$ & $14(1.86)$ & $26(1.81)$ & \\
\hline 2 ACEs & $13(1.90)$ & $30(3.98)$ & $43(2.94)$ & \\
\hline 3 ACEs & $49(7.17)$ & $62(8.23)$ & $111(7.70)$ & \\
\hline $4+\mathrm{ACEs}$ & $606(88.73)$ & $642(85.26)$ & $1248(86.99)$ & \\
\hline Prospective Binary ACE score & & & & $0(0.0)$ \\
\hline Less than 6 ACEs & $348(50.95)$ & $442(58.70)$ & $790(55.01)$ & \\
\hline 6 or more ACEs & $335(49.05)$ & $311(42.30)$ & $64,699(44.99)$ & \\
\hline Prospective LCA derived ACEs & & & & $0(0.0)$ \\
\hline Class 1: Low adversity & $43(6.30)$ & $70(9.30)$ & $113(7.87)$ & \\
\hline $\begin{array}{l}\text { Class 2: Moderate } \\
\text { adversity-dysfunction }\end{array}$ & $223(32.65)$ & $350(46.48)$ & $573(39.90)$ & \\
\hline Class 3: Moderate adversity-abuse & $127(18.59)$ & $106(14.08)$ & $233(16.23)$ & \\
\hline Class 4: High adversity & $290(42.46)$ & $227(30.15)$ & $517(36.00)$ & \\
\hline \multicolumn{5}{|l|}{ Single Retrospective ACEs } \\
\hline Physical abuse & $58(8.90)$ & $41(5.75)$ & $99(7.33)$ & $71(4.94)$ \\
\hline Sexual abuse & $16(2.47)$ & $36(5.05)$ & $52(3.76)$ & $74(5.15)$ \\
\hline Emotional abuse & $251(37.19)$ & $241(32.44)$ & $492(34.82)$ & $18(1.25)$ \\
\hline Parental divorce & $251(43.35)$ & $276(44.44)$ & $527(43.90)$ & $236(16.43)$ \\
\hline Parental death & $184(27.34)$ & $167(22.57)$ & $351(24.96)$ & $23(1.60)$ \\
\hline Household death & $191(33.39)$ & $199(32.20)$ & $390(32.80)$ & $246(17.13)$ \\
\hline Household substance abuse & $205(30.37)$ & $178(23.96)$ & $383(27.17)$ & $18(1.25)$ \\
\hline Household illness/disability & $240(35.50)$ & $277(37.48)$ & $517(36.49)$ & $21(1.46)$ \\
\hline Household legal trouble & $172(25.48)$ & $144(19.38)$ & $316(22.43)$ & $18(1.25)$ \\
\hline Chronic unemployment & $306(45.33)$ & $296(39.84)$ & $602(42.59)$ & $18(1.25)$ \\
\hline Exposure to IPV & $81(12.05)$ & $97(13.18)$ & $178(12.62)$ & $28(1.95)$ \\
\hline Exposure to violence & $222(33.04)$ & $160(21.83)$ & $382(27.44)$ & $31(2.16)$ \\
\hline \multicolumn{5}{|l|}{ Retrospective ACE category } \\
\hline 0 ACEs & $58(8.49)$ & $76(10.09)$ & $134(9.29)$ & \\
\hline $1 \mathrm{ACE}$ & $117(17.13)$ & $135(17.93)$ & $252(17.53)$ & \\
\hline 2 ACEs & $98(14.35)$ & $168(22.31)$ & $266(18.33)$ & \\
\hline 3 ACEs & $126(18.45)$ & $127(16.87)$ & $253(17.66)$ & \\
\hline 4+ ACEs & $284(41.58)$ & $247(32.80)$ & $531(37.19)$ & \\
\hline Retrospective Binary ACE score & & & & $0(0.0)$ \\
\hline Less than 6 ACEs & $582(85.21)$ & $677(89.91)$ & 1259 (87.67) & \\
\hline 6 or more ACEs & $101(14.79)$ & $76(10.09)$ & $177(12.33)$ & \\
\hline Retrospective LCA derived ACES & & & & $0(0.0)$ \\
\hline Class 1: Low adversity & $268(39.24)$ & $332(44.09)$ & $600(41.78)$ & \\
\hline $\begin{array}{l}\text { Class 2: Moderate } \\
\text { adversity-dysfunction }\end{array}$ & $184(26.94)$ & $203(16.96$ & $387(26.95)$ & \\
\hline Class 3: Moderate adversity-abuse & $109(15.96)$ & $125(16.60)$ & $234(16.30)$ & \\
\hline Class 4: High adversity & $122(17.86)$ & $93(12.35)$ & $215(14.97)$ & \\
\hline \multicolumn{5}{|l|}{ Outcomes } \\
\hline Psychological distress & $58(10.86)$ & $143(23.68)$ & $201(17.27)$ & $298(20.75)$ \\
\hline Social isolation & $73(13.67)$ & $45(7.45)$ & $118(10.56)$ & $298(20.75)$ \\
\hline Incomplete secondary education & $207(39.06)$ & $152(25.33)$ & $359(32.20)$ & $306(21.31)$ \\
\hline
\end{tabular}


Table 1. Cont.

\begin{tabular}{|c|c|c|c|c|}
\hline Variable & Male & Female & Total & Missing \\
\hline Unemployed & $242(45.32)$ & $254(42.12)$ & $496(43.72)$ & $299(20.82)$ \\
\hline Welfare receipt ${ }^{1}$ & $5(1.28)$ & $246(51.36)$ & $251(28.82)$ & $565(39.35)$ \\
\hline Criminality & $150(28.04)$ & $32(5.30)$ & $182(16.67)$ & $297(20.68)$ \\
\hline Substance use & $210(41.02)$ & $73(12.74)$ & $283(26.88)$ & $351(24.44)$ \\
\hline HIV infection & $52(11.13)$ & $96(16.78)$ & $148(13.96)$ & $397(27.65)$ \\
\hline \multicolumn{5}{|l|}{ Covariates } \\
\hline Sex & $683(47.56)$ & $753(52.44)$ & $1436(100.00)$ & $0(0.0)$ \\
\hline Socio-economic status at birth & & & & $115(8.01)$ \\
\hline Quintile 1 & $101(16.19)$ & $103(14.78)$ & $204(15.49)$ & \\
\hline Quintile 2 & $112(17.95)$ & $126(18.08)$ & $238(18.02)$ & \\
\hline Quintile 3 & $214(34.29)$ & $240(34.43)$ & $454(34.36)$ & \\
\hline Quintile 4 & $135(21.63)$ & $139(19.94)$ & $274(20.79)$ & \\
\hline Quintile 5 & $62(9.94)$ & $89(12.77)$ & $151(11.36)$ & \\
\hline Socio-economic status at 12 years & & & & $380(26.46)$ \\
\hline Quintile 1 & $114(23.12)$ & $123(21.85)$ & $237(22.49)$ & \\
\hline Quintile 2 & $164(33.27)$ & $169(30.02)$ & $333(31.65)$ & \\
\hline Quintile 3 & $72(14.60)$ & $88(15.63)$ & $160(15.12)$ & \\
\hline Quintile 4 & $54(10.95)$ & $71(12.61)$ & $125(11.78)$ & \\
\hline Quintile 5 & 89 (18.05) & $112(19.89)$ & $201(18.97)$ & \\
\hline Socio-economic status at 22 years & & & & $39(2.72)$ \\
\hline Quintile 1 & $209(31.48)$ & $230(31.38)$ & $439(31.43)$ & \\
\hline Quintile 2 & $106(15.96)$ & $116(15.83)$ & $222(15.90)$ & \\
\hline Quintile 3 & $154(23.19)$ & $139(18.96)$ & $293(21.08)$ & \\
\hline Quintile 4 & $109(16.42)$ & $139(18.96)$ & $248(17.69)$ & \\
\hline Quintile 5 & $86(12.95)$ & $109(14.87)$ & $195(13.91)$ & \\
\hline Maternal age at birth of child & & & & $2(0.14)$ \\
\hline $15-18$ years & $72(10.54)$ & $89(11.85)$ & $161(11.20)$ & \\
\hline 19-24 years & $233(34.11)$ & $254(33.82)$ & $487(33.97)$ & \\
\hline $25-34$ years & $305(44.66)$ & $331(44.07)$ & $636(44.37)$ & \\
\hline $35-46$ years & $73(10.69)$ & $77(10.25)$ & $150(10.47)$ & \\
\hline Maternal education, mean (SD) & $9.57(2.63)$ & $9.71(2.60)$ & $9.64(2.62)$ & $106(7.38)$ \\
\hline Paternal education, mean (SD) & $10.49(2.43)$ & $10.62(2.47)$ & $10.56(2.43)$ & $426(29.67)$ \\
\hline
\end{tabular}

${ }^{1}$ Welfare receipt calculated for the sub-sample who have children $(n=871)$.

\section{Results}

\subsection{Characteristics of the Sample}

Among the 1436 participants in the study, 47.5\% were male and 52.4\% were female (Table 1). Similar proportions of participants were born to young mothers $(11.2 \%$ to mothers aged 15-18 at birth and $10.4 \%$ to mothers aged 35-44+ at birth), with the majority (78.3\%) born to mothers aged between 19-34. Fathers had on average 1 year of additional schooling (mean $=10.5)$ than mothers (mean $=9.5)$. At birth, $15.4 \%$ of participants were in the lowest wealth quintile compared to $11.4 \%$ in the highest, at 12 -years-old, $22.4 \%$ were in the lowest quintile and $19.0 \%$ in the highest, and at age $22,31.4 \%$ fell into the lowest quintile and $13.9 \%$ in the highest, leaving a shrinking middle across quintile $2-4$ from birth to age 22 of $73.1 \%, 58.5 \%$, and $54.6 \%$, respectively.

\subsection{Prevalence of Human Capital Outcomes}

The most prevalent adverse outcomes were unemployment (43.7\%), incomplete secondary education (32.3\%), substance use $(26.9 \%)$, and welfare receipt $(28.2 \%)$. Just over half of the females with children $(51.4 \%$ ) receive welfare compared to $1.3 \%$ of males caring for children. While both parents are eligible to receive welfare in the form of the Child Support Grant in South Africa, the greatest number of recipients (over 95\% nationally and $98 \%$ in this sample), are women [37]. Females reported higher rates of psychological distress (23.7\% compared to $10.9 \%$ ), and HIV infection (16.8\% compared to $11.1 \%)$ than males. Males reported higher rates of social isolation (13.7\% compared to $7.5 \%)$, incomplete 
secondary education (39.1\% compared to $25.3 \%)$, criminality $(28.0 \%$ compared to $5.3 \%)$, and substance use (41.0\% compared to $12.7 \%)$ compared to females.

\subsection{Prevalence of ACEs}

\subsubsection{Single ACEs}

The most commonly reported prospective ACEs were chronic unemployment $(86.2 \%)$, exposure to violence $(70.4 \%)$, household death $(63.1 \%)$, and household illness or disability (62.6\%). Prospectively, 54.7\% of participants reported physical abuse, 38.1\% reported sexual abuse, and 35.7\% reported emotional abuse. Reported exposure to all single ACEs, with the exception of parental death, decreased in retrospective reports. The most common retrospective ACEs were parental divorce (43.9\%), chronic unemployment (42.6\%), and household illness or disability (36.5\%). Retrospectively, physical abuse was reported at a rate of $7.3 \%$, sexual abuse at $3.8 \%$, and emotional abuse or neglect at $34.8 \%$.

\subsubsection{Cumulative ACEs}

Similar patterns are seen in the prevalence of cumulative ACEs. While $87.0 \%$ of participants report four or more ACEs prospectively, 37.2\% report four or more ACEs retrospectively. The proportion of participants reporting no ACEs remains low both prospectively $(0.6 \%)$ and retrospectively $(9.3 \%)$. Using the binary cut-off, $55.0 \%$ of participants report less than six ACEs prospectively, and 87.7\% report less than six ACEs retrospectively.

\subsubsection{Clustered ACEs}

The best fitting LCA models identified four classes for both the prospective and retrospective ACEs: low adversity (7.9\% prospective, $41.8 \%$ retrospective); moderate adversitydysfunction (39.9\% prospective, $27.0 \%$ retrospective); moderate adversity-abuse (16.2\% prospective, $16.3 \%$ retrospective); and high-adversity (36.0\% prospective, $15.0 \%$ retrospective).

Figure 1 shows the predicted probability of each adversity for each of the prospective and retrospective classes that led to the characterization of the classes. For prospective ACEs, low adversity was the smallest class, with the highest probabilities being a $28 \%$ chance of living in a household in which a member has died and $23 \%$ chance of living in a household where a member has a serious chronic illness or disability. Inclusion in the moderate adversity-dysfunction class was driven by ACEs related to household dysfunction, namely high chances of chronic unemployment $(88 \%)$, parent divorce $(47 \%)$, household death (63\%), and household substance abuse (43\%), among others. Participants in moderate adversity-abuse had a $66 \%$ chance of reporting physical abuse, $46 \%$ chance of reporting emotional abuse, as well as high levels of chronic unemployment (69\% chance), exposure to IPV (83\%), and community violence (94\%). In the high adversity class, the probability of experiencing any one of the ACEs was greater than $40 \%$ for 11 of the 13 ACEs.

For retrospective clusters of ACEs, the low adversity group was characterized by highest probabilities for parental divorce and household death (31\% each). Participants in the moderate adversity-dysfunction class had a $26 \%$ chance of reporting emotional abuse compared to participants in moderate adversity-abuse with a $66 \%$ chance of reporting emotional abuse. While those participants in moderate adversity-abuse were very unlikely to report chronic unemployment and household legal trouble compared to participants in moderate adversity-dysfunction who were almost certainly experiencing those two ACEs. The high adversity class had a more than a $40 \%$ chance of reporting seven of the 12 ACEs, with an $81 \%$ chance of emotional abuse, $73 \%$ chance of household illness / disability, $64 \%$ chance of household substance abuse, and $60 \%$ chance of parent divorce, and were more likely to report chronic unemployment (100\%) and household legal trouble (100\%). 


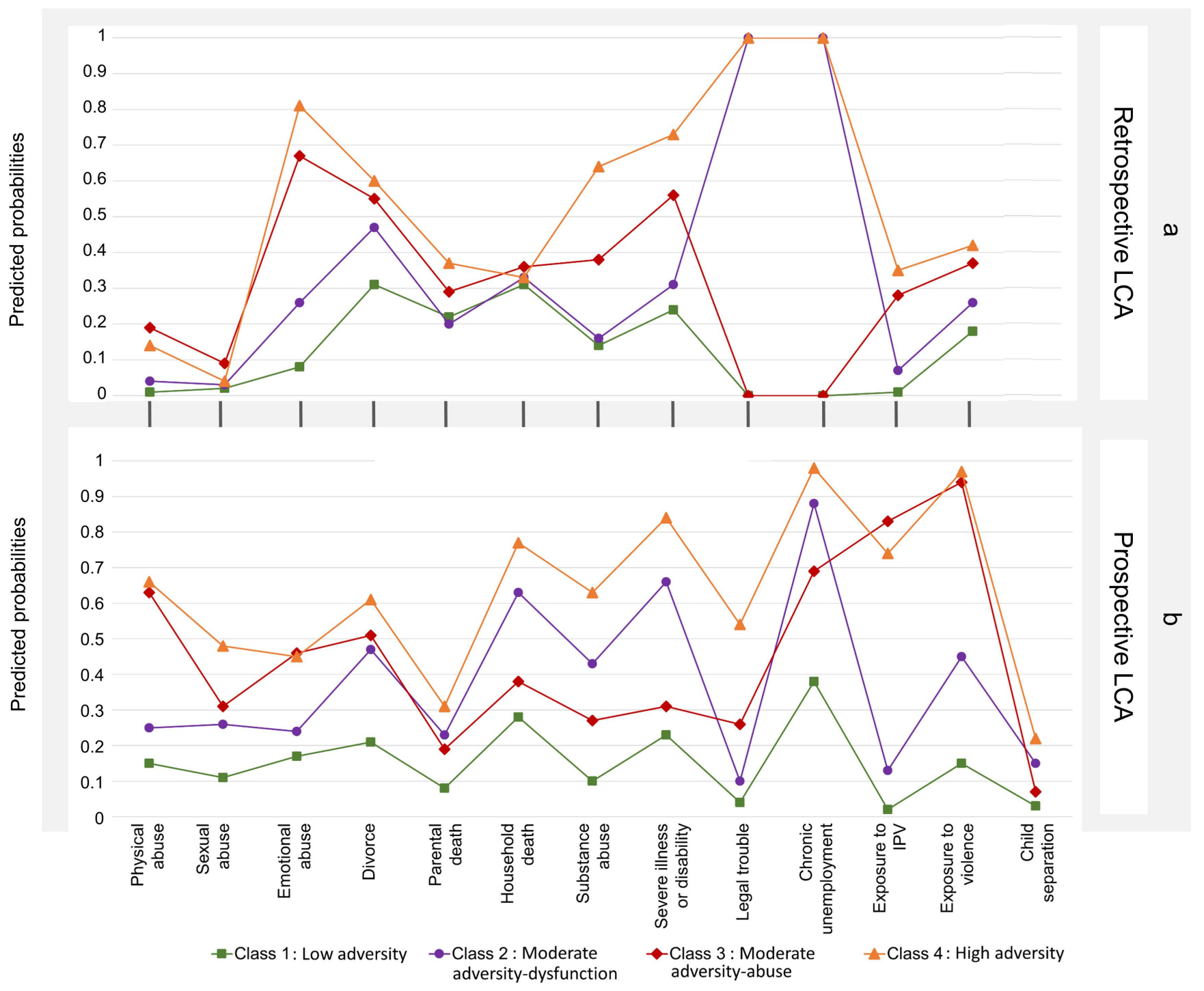

Figure 1. Predicted probabilities for latent class analyses of: (a) retrospective ACEs; (b) prospective ACEs.

\subsection{Associations between ACEs and Human Capital Outcomes}

Figure 2 illustrates the significant findings from adjusted logistic regressions displayed for the associations between both prospective and retrospective single ACEs and human capital outcomes for the total sample, which are disaggregated by sex. Figure 3 shows the significant adjusted associations between prospective and retrospective cumulative and clustered ACEs and human capital outcomes, again for the total sample and disaggregated by sex.

\subsubsection{Cumulative ACEs and Human Capital Outcomes}

The risk for poorer outcomes increased along with the number of ACEs whether reported prospectively or retrospectively. Reporting more than six ACEs prospectively was significantly associated with greater odds of psychological distress (OR 1.63, CI 1.19-2.23), incomplete schooling (OR 1.51, CI 1.15-1.99), unemployment (OR 1.28, CI 1.10-1.64), and criminality (OR 1.80, CI 1.28-2.54) compared to reporting less than six ACEs in the full sample-all of which were only significant for males when disaggregated by sex (OR 1.97, CI 1.11-3.48; OR 1.74 CI 1.20-2.53; OR 1.47, CI 1.04-2.09; OR 1.84, CI 1.22-2.76, respectively). Reporting more than six ACEs retrospectively was associated with increased likelihood of psychological distress (OR 1.72, CI 1.13-1.32) and criminality (OR 1.69, CI 1.09-2.63) 
compared to less than six ACEs. Females retrospectively reporting three ACEs and four or more ACEs were 3.5 (CI 1.13-10.38) and 5.4 (CI 2.04-14.51) times more likely to report psychological distress, respectively. Females were 2.8 times (CI 1.18-6.5) more likely to engage in criminality if they experience more than six ACEs and males are more than three times more likely to engage in criminality when they report more than one ACE (OR 3.10, CI 1.05-9.14 for two ACEs; OR 3.97, CI 1.41-11.21 for three ACEs; and OR 3.64, CI 1.27-10.47 for more than four ACEs).

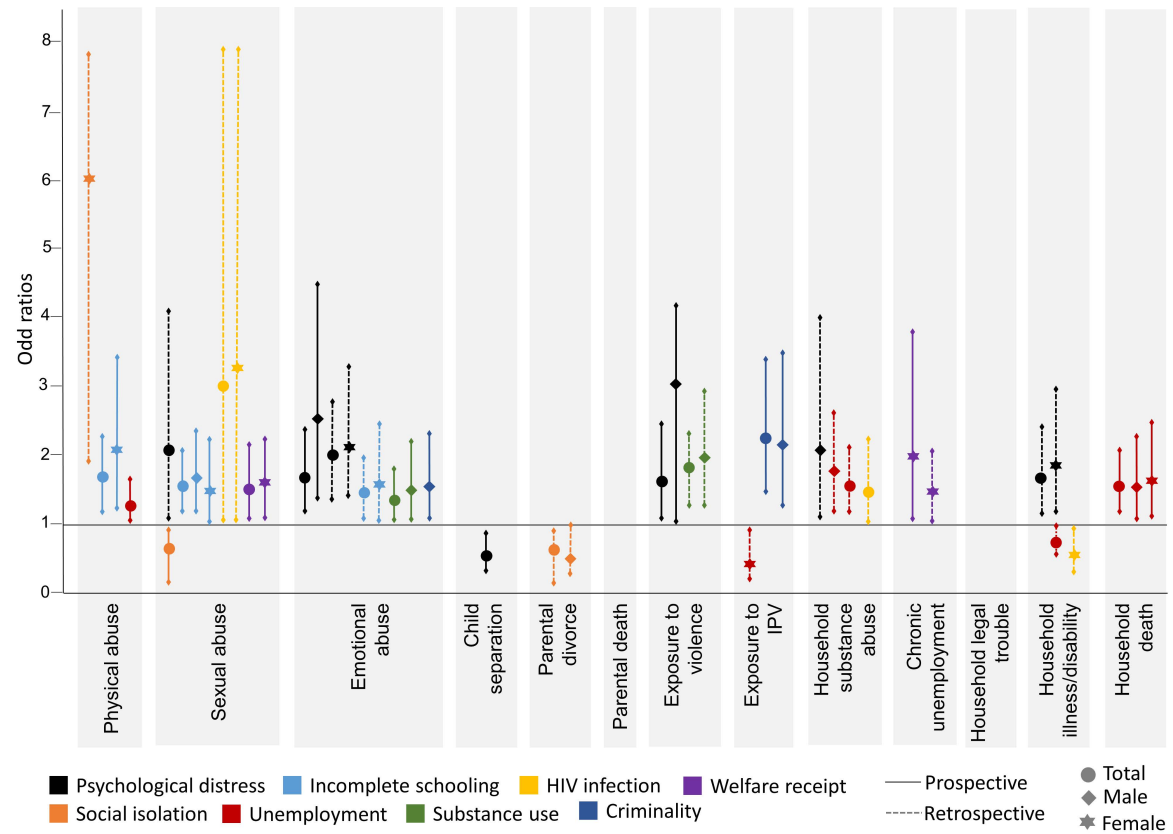

Figure 2. Significant adjusted associations (odds ratios) between single ACEs and human capital outcomes, for the total sample and disaggregated by sex.

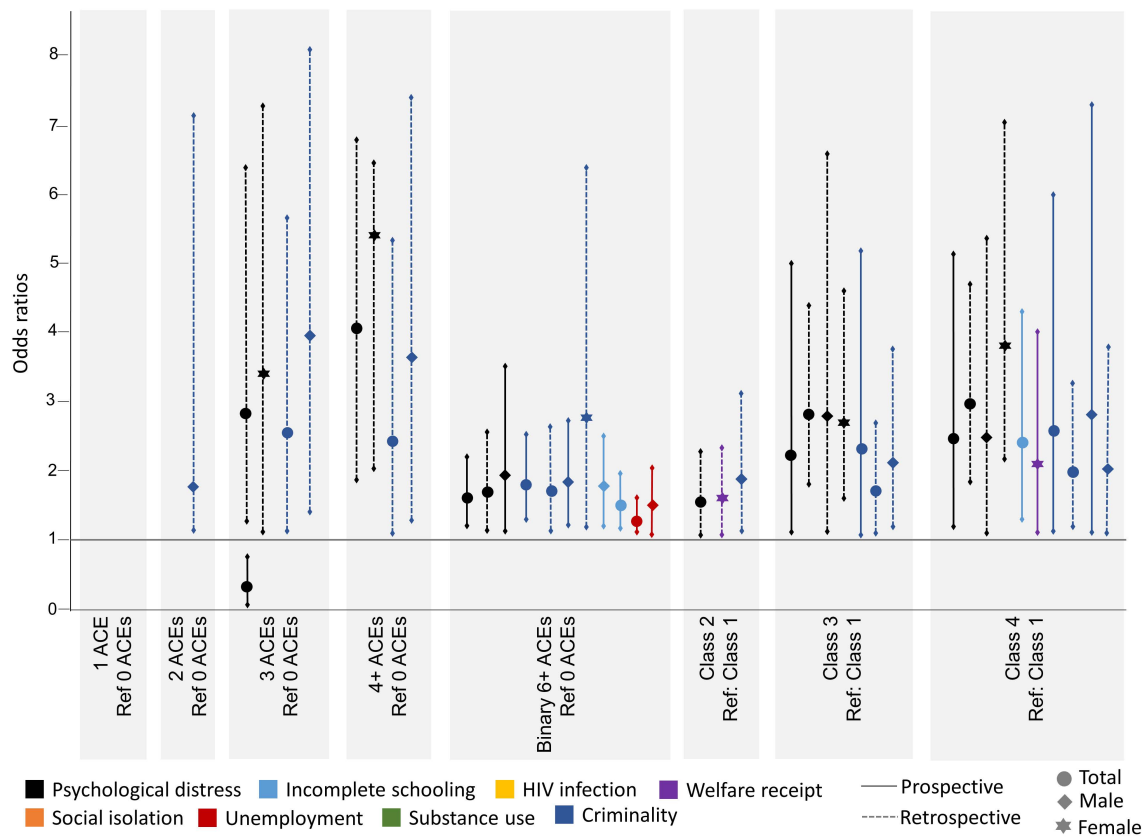

Figure 3. Significant adjusted associations (odds ratios) between cumulative and clustered ACEs and human capital outcomes, for the total sample and disaggregated by sex. 


\subsubsection{Clustered ACEs and Human Capital Outcomes}

Prospectively, compared to the low adversity cluster, the odds of experiencing psychological distress in the moderate adversity-dysfunction cluster are 2.8 (1.18-6.64) for males and 2.71 (1.58-4.63) for females. Individuals in the moderate adversity-abuse cluster are 2.23 times (1.10-5.04) more likely to experience psychological distress and 2.29 times (1.01-5.22) more likely to engage in criminality. Females who fall in the moderate adversityabuse cluster have a greater likelihood of welfare receipt (OR 1.60, CI 1.06-2.41). The high adversity cluster has greater odds of experiencing psychological distress (OR 2.47, CI 1.19-5.09), incomplete schooling (OR 2.39, CI 1.33-4.32), and criminality (OR 2.60, CI 1.12-6.02).

Retrospectively, when comparing all other clusters to the low adversity group, there is a greater likelihood of psychological distress. The association is strongest in the high adversity cluster (OR 2.97, CI 1.86-4.74), followed by the moderate adversity-abuse group (OR 2.82, CI 1.8-4.41), and lastly the moderate adversity-dysfunction cluster (OR 1.52, CI 1.01-2.29). The moderate adversity-abuse group is also associated with criminality (OR 1.69, CI 1.04-2.73). Males in the high adversity cluster have increased odds for criminality (OR 2.84, CI 1.10-7.34) and females in the same group are more likely to be receiving welfare assistance (OR 2.11, CI 1.10-4.05).

\section{Discussion}

\subsection{Adverse Childhood Experiences and Human Capital}

This study aimed to examine the relationship between ACEs and adult human capital outcomes using unique and under-utilized measurement methods of ACEs in comparison to these human capital outcomes. To our knowledge, no other study has drawn on this methodological approach in studying ACEs and none were conducted in the LMIC context of sub-Saharan Africa. This study found that ACEs can be linked to poor human capital outcomes in young adulthood in an urban South African sample. There are a number of individual adversities that are independently associated with human capital outcomes, particularly the abuse-level variables. For example, incomplete schooling is associated with physical, sexual, and emotional abuse; social isolation is associated with physical abuse; and welfare receipt and HIV infection are associated with sexual abuse. The persistent and independent impact that these abuse-level experiences have on health and wellbeing is supported in previous analysis [17]. Individual household dysfunction adversities also play a role in poor human capital outcomes. Household substance abuse was linked to psychological distress and unemployment; exposure to violence was linked to psychological distress and substance use; and household death was linked to unemployment. The cumulative effects of adversity in childhood were also evident. Exposure to greater levels of ACEs, irrespective of their type, was linked to poorer outcomes. Similarly, the clustering of ACEs could be linked to negative human capital outcomes across low-high and dysfunctionabuse planes. There were stronger associations between negative outcomes and ACEs when the high adversity group was compared to the low adversity group, and similarly when the group likely to experience more abuse was compared to the group likely to experience more household dysfunction.

Globally, and particularly in LMICs such as South Africa, psychological distress contributes substantially to the burden of disease [38]. The prevalence of psychological distress - characterized here by depression, anxiety, and somatic symptoms-in this sample $(17.3 \%)$ is lower than reported in a nationally representative South African survey (23.9\%) [39], although the current study focused on participants expressing the highest levels of psychological distress. Experiences of sexual and emotional abuse, as well as exposure to violence, and substance abuse and severe illness/disability in the household as a child were risk factors for presenting with high psychological distress in adulthood. Individuals with more than three ACEs and in any cluster other than the low adversity group were significantly more likely to experience psychological distress. A growing body of research, including in this cohort [17], have linked ACEs to mental illness in various forms: 
internalizing and externalizing problems [40], depressive and anxiety disorders [41,42], and personality disorders $[43,44]$. Some of the possible mechanisms from early adversity to mental ill health include the disruption of adaptive emotion regulation processes, alterations in the structure and function of key areas of the brain, and the development of maladaptive coping strategies [45].

Social isolation, or the objective lack of interaction with others [46], was significantly associated with reported physical abuse in childhood in this study. The implications of prolonged social isolation on mental and physical health in younger populations is still emerging, but evidence of resultant cognitive decline in middle-aged populations [47] and mortality in mixed-aged populations $[48,49]$ is available. As more and more research is conducted, driven by COVID-19-induced social isolation, the persistent and serious consequences of social isolation for health and wellbeing are being recognized [50].

The South African schooling system is divided into four phases, with mandatory attendance in the first three quarters and an optional $4^{\text {th }}$ phase that results in graduation out of the school system [51]. Despite high rates of enrollment in both primary and secondary schooling [52], the rates of incompletion for the latter are alarmingly high, with between $50-60 \%$ of learners not completing their secondary schooling [53]. Rates of secondary school incompletion in the current sample are much lower $(32.2 \%)$ than the national average $(\sim 50.0 \%)$, but follow the same trend of females more likely to complete than males [54]. The capacity to progress out of school into tertiary education and/or employment is crucial for maximized human capital. Reports of physical abuse, sexual abuse, and emotional abuse in childhood as well as experiencing six or more ACEs cumulatively and being placed in the high adversity cluster are significant predictors for incomplete schooling in this study. Similar findings are seen in another birth cohort; retrospective physical and sexual abuse were significantly associated with failing to achieve secondary school qualifications, but these associations lost significance after adjusting for social, parental, and individual factors [55]. The pathway from abuse to educational attainment is partially through performance at school. Learners who reported abuse and maltreatment were likely to perform poorly on tests, repeat grades, and encounter more problems with schoolwork [56,57].

Inextricably linked to incomplete schooling is unemployment, given that income poverty and inequality in South Africa are driven by disparities in qualifications and skills [58]. South Africa has an average unemployment rate of $34.4 \%$, with youth unemployment (15-24-year-olds) at $64.4 \%$ and young adult unemployment (25-34-year-olds) at $42.9 \%$ [59]. Young adults in this study have similar rates of unemployment at $43.7 \%$, risk factors for which were physical abuse, household death, and household substance abuse, as well as reporting six or more ACEs. A cross-sectional study looking at retrospective ACEs found that adults with four or more ACEs were 2.3 times more likely to be unemployed compared to adults with no ACEs [60], and other studies have linked early adversity to unemployment in similar ways [61-63]. Associations between ACEs and human capital outcomes such as unemployment and incomplete schooling are difficult to tease out given the high youth unemployment rates and poorly ranked education system in South Africa [64]. There is likely an interplay between exposure to ACEs and contextual and structural factors. For example, with a national dependency ratio of $52.7 \%$ and $70 \%(59 \%$ in 2003$)$ of children living in households with at least one working adult [65], a household death may impact household income, ability to attend school, and subsequent employment. In fact, one study estimates that a 1 percentage point increase in school attendance is associated with an average decrease of 6 percentage points in the dependency ratio [66].

Sexual abuse in childhood is independently associated with welfare receipt in adulthood for females, as was inclusion in the moderate adversity-abuse and high adversity groups. General social protection measures in South Africa have made substantial contributions to poverty reduction [67], and the Child Support Grant in particular has had multiple benefits for vulnerable children and families [68-70]. Nevertheless, the receipt of the grant is a good indication that the household is income- and resource-poor [71]. 
HIV infection was also independently associated with sexual abuse in childhood for females. Prevalence of HIV positive status in the sample was $14 \%$, mirroring the national population at $14 \%$ and below the 15-49-year-old age group at $20 \%$ [72]. A crosssectional study among 2042 post-natal women in Harare, Zimbabwe found that 15\% of the women tested positive, and that women who reported child sexual abuse were three times as likely to test positive for HIV [73]. The mechanisms for infection could operate directly, with infection occurring as a result of forced sex or rape, or indirectly through the weakening of psychological wellbeing and other protective factors that could lead to risky behaviors [74,75]. A South African study found that physical, sexual, and emotional abuse and neglect were associated with a range of HIV-risk behaviors [76].

Substance use in adulthood was associated with emotional abuse and exposure to violence in childhood, but only for males in the sample. Substance abuse has long been a global health challenge contributing to personal disability and mortality and economic burdens to society [77]. Studies in South Africa and worldwide have linked childhood trauma directly and indirectly, through mediation, to substance use in adulthood [78,79]. Furthermore, a recent meta-analysis suggests that individuals with four or more ACEs were twice as likely to be current smokers or heavy drinkers and six times as likely to drink problematically than those with no ACEs [7]. Criminality was linked to emotional abuse and exposure to IPV in childhood, as was inclusion in the moderate adversity-abuse and high adversity clusters. Females were almost three times more likely to engage in criminality if they reported six or more ACEs whereas males were 3-4 times more likely with more than one ACE. A study on siblings demonstrated that the likelihood of committing a crime doubled with experiences of child abuse and neglect [80]. Compared to females, relatively low levels of adversity could be linked to criminality in males; however, our analyses did not differentiate between serious and petty, or violent and non-violent crime, which may contribute to these differences. Findings in the literature are divergent, with some studies arguing for similar propensities for females and males to engage in serious, persistent, and violent crime [81], a study where males were at greater risk of committing a violent offense [82], and another where females were more likely to be arrested for violence [83]. The co-occurrence of substance use and criminality is well documented $[84,85]$, and recent research has examined pathways showing that for moderate-to-high substance users, ACEs are linked to increased criminality [86]. These findings are interesting and may partly explain the sex differences in expressions of criminality.

\subsection{Measuring ACEs}

Comparing different approaches to ACEs measurement reveals several insights with regard to human capital outcomes. Individual ACEs, particularly prospective physical, sexual, and emotional abuse and exposure to violence can be linked to poorer outcomes. Retrospectively, these single ACEs, as well as household dysfunction indicators, are associated with poorer outcomes. Part of this may be that children may not be fully aware of household dysfunction and its extent or severity, as it occurs prospectively, and they may piece together these reports in hindsight. Alternatively, only those participants who experienced severe household dysfunction may be reporting so retrospectively. Another possibility is that prospective and retrospective measures of ACEs may be identifying different groups of individuals within a sample. Consequently, those identified as having greater ACEs prospectively may have different pathways to poor outcomes than those identified as having had greater ACEs retrospectively [22].

Cumulative measures of ACEs show graded relationships with gradual increases in risk for poor outcomes, demonstrating their ability to show the snowballing effect of ACEs. Clustered ACEs improve on these measures through their ability to make qualitative distinctions between ACEs that tend to co-occur. However, the usefulness of the ACEs score as a rapid screening tool should not be ignored. Cut-offs for ACE categories should be made in consideration with the distribution of ACEs among the population. The conventional cut-off at four ACEs in the five-level ACEs categories does not appear to be adequate 
at distinguishing between those who are at a greater risk for poorer outcomes in high adversity settings. However, this five-level ACEs indicator, popularized by the CDC Kaiser study [10], appears to be more indicative of poorer outcomes when ACEs are assessed retrospectively compared to prospectively.

\subsection{Implications of Findings}

Single ACEs at the individual level-physical, sexual, and emotional abuse-have persistent and long-term impacts on a range of human capital outcomes. Exposure to high levels of adversity accumulated over childhood can lead to equally poor outcomes in adulthood. Patterns of ACEs can differentially predict human capital outcomes-the two distinct patterns are low-high and dysfunction-abuse. Individuals who fall into a high adversity category, characterized by generalized adversity across a range of indicators, are prone to poorer human capital outcomes. Prospectively, individuals with a high likelihood of abuse and the co-occurrence of household dysfunction in the form of IPV, chronic unemployment, and exposure to violence, are linked to adverse mental health. Retrospectively, emotional abuse and some household dysfunction can be linked to poorer human capital outcomes even in the absence of poverty proxied by chronic unemployment. Individual ACEs and a moderate amount of adversity may contribute to resilience and protect against certain poor human capital outcomes. Both individual and cumulative ACEs - the same type and number of ACEs - appear to affect males and females in different ways, leading to different outcomes. Therefore, demonstrating that disaggregation by sex is important. In further support of this, one study that assessed gendered profiles of adversity concluded that there are separate and distinct patterns of childhood adversities, with females experiencing more complex and varied patterns [29].

\subsection{Strengths and Limitations}

The Bt30 sample is situated in a previously disadvantaged urban area in South Africa, limiting the generalizability of findings. The prevalence of ACEs, both prospectively and retrospectively, is considerably higher than global and meta-analytic estimates [7]. However, ACEs evidence in low-income, high-violence settings with widespread adversity across the life course is slowly emerging [19,87-89] and highlighting important similarities and differences in the field. Bt30 is one of few cohorts in an LMIC that has reached young adulthood-the period in which human capital disparities are likely to emerge [90]. This cohort is also one of few with both prospective and retrospective data on ACEs, especially in LMIC contexts; comparisons between prospective and retrospective reports of ACEs are key to understanding the risk mechanisms that underlie poor outcomes. This is particularly true given limitations around self-reported retrospective data which can be open to social desirability bias, recall error and the like. The authors concede that the retrospective self-reports of ACEs may be exposed to such bias but counter that (a) self-reports may be closer to true estimates, taking into account unreported and unobserved adversity [91], and (b) that both self-reported retrospective and prospective measures of adversity show substantial links to poor outcomes [92], supporting the usefulness of these self-reported retrospective accounts of adversity.

\section{Conclusions}

The measurement of ACEs is more complicated than often assumed. Both timingprospective and retrospective reports-and the approaches of measuring ACEs can give differing insights into their links to adverse outcomes. Consequently, thought needs to be given to how ACEs are used in practice and policy.

Given South Africa's strained economy-similar to other LMICs-it is critical that efforts are made to cultivate and protect human capital. The prevention of abuse in childhood-physical, sexual, and emotional abuse-must be a priority. Families need to be supported to mitigate the effects of household dysfunction. Evans and Kim suggest that "cumulative rather than singular exposure to a confluence of psychosocial and physical 
environmental risk factors is a potentially critical aspect of the environment of childhood poverty" (p. 77) [93]. For resource-poor countries, understanding the potential impact of early adversity across the life course is critical to breaking the intergenerational cycle of poverty.

Supplementary Materials: The following supporting information can be downloaded at: https: / / www.mdpi.com/article/10.3390/ijerph19031799/s1, Table S1: Adverse childhood experiences questionnaire; Table S2: Model fit indices for latent class analysis of prospective and retrospective ACEs; Table S3: Crude associations between single, cumulative and clustered prospective ACEs and health and human capital outcomes; Table S4: Crude associations between single, cumulative and clustered retrospective ACEs and health and human capital outcomes; Table S5: Adjusted associations between single, cumulative and clustered prospective ACEs and health and human capital outcomes; Table S6: Adjusted associations between single, cumulative and clustered retrospective ACEs and health and human capital outcomes; Table S7: Adjusted associations between single, cumulative and clustered prospective ACEs and health and human capital outcomes, by sex; Table S8: Adjusted associations between single, cumulative and clustered retrospective ACEs and health and human capital outcomes, by sex.

Author Contributions: Conceptualization, S.N.N., S.A.N. and L.M.R.; methodology, S.N.N., L.M.R., M.O., S.B. and M.N.A.; formal analysis, S.N.N. and M.O.; writing-original draft preparation, S.N.N.; writing-review and editing, S.N.N., M.O., S.B., M.N.A., L.M.R. and S.A.N.; visualization, S.N.N.; funding acquisition, S.A.N. and L.M.R. All authors have read and agreed to the published version of the manuscript.

Funding: The adult outcome data collection at 28 years of age was funded by the Bill \& Melinda Gates Foundation, Seattle, WA (OPP1164115).

Institutional Review Board Statement: The study was conducted according to the guidelines of the Declaration of Helsinki and approved by the Witwatersrand University Committee for Research on Human Subjects (Ref. No. M010556, 2017).

Informed Consent Statement: Informed consent was obtained from all subjects involved in the study.

Data Availability Statement: Bt30 is housed in the DSI-NRF Centre of Excellence in Human Development at the University of the Witwatersrand and requests for data can be made through https: / / www.wits.ac.za/coe-human/open-access-datasets/ (accessed on 15 January 2022). Alternatively, the corresponding author of the study can be contacted for access to the data.

Acknowledgments: Support for the Birth to Thirty cohort has been provided by the Medical Research Council of South Africa, the Human Sciences Research Council, the University of the Witwatersrand and the DSI-NRF Centre of Excellence in Human Development at the University of the Witwatersrand, Johannesburg.

Conflicts of Interest: The authors declare no conflict of interest. The funders had no role in the design of the study; in the collection, analyses, or interpretation of data; in the writing of the manuscript, or in the decision to publish the results.

\section{Abbreviations}

ACEs Adverse Childhood Experiences

AIC Akaike's Information Criteria

BIC Baysian Information Criteria

Bt30 Birth to Thirty

CI Confidence intervals

DSI-NRF Department of Science and Innovation-National Research Foundation

HIV Human immunodeficiency virus

IPV Intimate partner violence

LCA Latent class analysis

LMIC Lower-middle-income country

OR Odds ratios

SSABIC Sample-sex adjusted Bayesian Information Criteria 


\section{References}

1. $\quad$ Lim, S.S.; Updike, R.L.; Kaldjian, A.S.; Barber, R.M.; Cowling, K.; York, H.; Friedman, J.; Xu, R.; Whisnant, J.L.; Taylor, H.J.; et al. Measuring human capital: A systematic analysis of 195 countries and territories, 1990-2016. Lancet 2018, 392, 1217-1234. [CrossRef]

2. Richter, L.M.; Ahun, M.N.; Besharati, S.; Naicker, S.N.; Orri, M. Adolescent Mental Health Problems and Adult Human Capital: Findings from the South African Birth to Twenty Plus Cohort at 28 Years of Age. J. Adolesc. Health 2021, 69, 782-789. [CrossRef] [PubMed]

3. Alderman, H. No Small Matter: The Impact of Poverty, Shocks, and Human Capital Investments in Early Childhood Development; World Bank Publications: Washington, DC, USA, 2011.

4. Nandi, A.; Behrman, J.R.; Bhalotra, S.; Deolalikar, A.B.; Laxminarayan, R. The Human Capital and Productivity Benefits of Early Childhood Nutritional Interventions; World Bank: Washington, DC, USA, 2017; pp. 385-402.

5. Liming, K.W.; Grube, W.A. Wellbeing Outcomes for Children Exposed to Multiple Adverse Experiences in Early Childhood: A Systematic Review. Infant Ment. Health J. 2018, 35, 317-335. [CrossRef]

6. Petruccelli, K.; Davis, J.; Berman, T. Adverse childhood experiences and associated health outcomes: A systematic review and meta-analysis. Child Abus. Negl. 2019, 97, 104127. [CrossRef]

7. Hughes, K.; Bellis, M.A.; Hardcastle, K.A.; Sethi, D.; Butchart, A.; Mikton, C.; Jones, L.; Dunne, M.P. The effect of multiple adverse childhood experiences on health: A systematic review and meta-analysis. Lancet Public Health 2017, 2, e356-e366. [CrossRef]

8. Toro, P.A. Developmental effects of child abuse: A review. Child Abus. Negl. 1982, 6, 423-431. [CrossRef]

9. Vizard, E.; Gray, J.; Bentovim, A. The impact of child maltreatment on the mental and physical health of child victims: A review of the evidence. BJPsych Adv. 2021, 28, 60-70. [CrossRef]

10. Felitti, V.J.; Anda, R.F.; Nordenberg, D.; Williamson, D.F.; Spitz, A.M.; Edwards, V.; Koss, M.P.; Marks, J.S. Relationship of Childhood Abuse and Household Dysfunction to Many of the Leading Causes of Death in Adults: The Adverse Childhood Experiences (ACE) Study. Am. J. Prev. Med. 1998, 14, 245-258. [CrossRef]

11. Struck, S.; Stewart-Tufescu, A.; Asmundson, A.J.; Asmundson, G.G.; Afifi, T.O. Adverse childhood experiences (ACEs) research: A bibliometric analysis of publication trends over the first 20 years. Child Abus. Negl. 2021, 112, 104895. [CrossRef]

12. A Bellis, M.; Hughes, K.; Ford, K.; Rodriguez, G.R.; Sethi, D.; Passmore, J. Life course health consequences and associated annual costs of adverse childhood experiences across Europe and North America: A systematic review and meta-analysis. Lancet Public Health 2019, 4, e517-e528. [CrossRef]

13. Lanier, P.; Maguire-Jack, K.; Lombardi, B.; Frey, J.; Rose, R.A. Adverse Childhood Experiences and Child Health Outcomes: Comparing Cumulative Risk and Latent Class Approaches. Matern. Child Health J. 2017, 22, 288-297. [CrossRef] [PubMed]

14. Pinto, R.; Correia, L.; Maia, Â. Assessing the Reliability of Retrospective Reports of Adverse Childhood Experiences among Adolescents with Documented Childhood Maltreatment. J. Fam. Violence 2014, 29, 431-438. [CrossRef]

15. Dube, S.R.; Felitti, V.J.; Dong, M.; Giles, W.H.; Anda, R.F. The impact of adverse childhood experiences on health problems: Evidence from four birth cohorts dating back to 1900. Prev. Med. 2003, 37, 268-277. [CrossRef]

16. Merrick, M.T.; Ports, K.A.; Ford, D.C.; Afifi, T.O.; Gershoff, E.T.; Grogan-Kaylor, A. Unpacking the impact of adverse childhood experiences on adult mental health. Child Abus. Negl. 2017, 69, 10-19. [CrossRef]

17. Naicker, S.N.; Norris, S.A.; Richter, L.M. Secondary analysis of retrospective and prospective reports of adverse childhood experiences and mental health in young adulthood: Filtered through recent stressors. eClinicalMedicine 2021, 40, 40. [CrossRef]

18. Jackson, D.; Testa, A.; Semenza, D.; Vaughn, M. Parental Incarceration, Child Adversity, and Child Health: A Strategic Comparison Approach. Int. J. Environ. Res. Public Health 2021, 18, 3384. [CrossRef]

19. Samia, P.; Premji, S.; Tavangar, F.; Yim, I.S.; Wanyonyi, S.; Merali, M.; Musana, W.; Omuse, G.; Forcheh, N.; Dosani, A.; et al. Adverse Childhood Experiences and Changing Levels of Psychosocial Distress Scores across Pregnancy in Kenyan Women. Int. J. Environ. Res. Public Health 2020, 17, 3401. [CrossRef]

20. Lacey, R.E.; Howe, L.D.; Kelly-Irving, M.; Bartley, M.; Kelly, Y. The Clustering of Adverse Childhood Experiences in the Avon Longitudinal Study of Parents and Children: Are Gender and Poverty Important? J. Interpers. Violence 2020. [CrossRef]

21. Shin, S.H.; McDonald, S.E.; Conley, D. Patterns of adverse childhood experiences and substance use among young adults: A latent class analysis. Addict. Behav. 2018, 78, 187-192. [CrossRef]

22. Baldwin, J.R.; Reuben, A.; Newbury, J.B.; Danese, A. Agreement Between Prospective and Retrospective Measures of Childhood Maltreatment: A Systematic Review and Meta-analysis. JAMA Psychiatry 2019, 2019. 76, 584-593. [CrossRef]

23. Reuben, A.; Moffitt, T.E.; Caspi, A.; Belsky, D.W.; Harrington, H.; Schroeder, F.; Hogan, S.; Ramrakha, S.; Poulton, R.; Danese, A. Lest we forget: Comparing retrospective and prospective assessments of adverse childhood experiences in the prediction of adult health. J. Child Psychol. Psychiatry 2016, 57, 1103-1112. [CrossRef] [PubMed]

24. Naicker, S.N.; Norris, S.; Mabaso, M.; Richter, L.M. An analysis of retrospective and repeat prospective reports of adverse childhood experiences from the South African Birth to Twenty Plus cohort. PLoS ONE 2017, 12, e0181522. [CrossRef] [PubMed]

25. Shonkoff, J.P.; Garner, A.S. The lifelong effects of early childhood adversity and toxic stress. Pediatrics 2012, 129, e232-e246. [CrossRef] [PubMed]

26. Shonkoff, J.P. Building a New Biodevelopmental Framework to Guide the Future of Early Childhood Policy. Child Dev. 2010, 81, 357-367. [CrossRef] 
27. Manyema, M.; Norris, S.A.; Richter, L.M. Stress begets stress: The association of adverse childhood experiences with psychological distress in the presence of adult life stress. BMC Public Health 2018, 18, 835. [CrossRef]

28. Leban, L.; Gibson, C.L. The role of gender in the relationship between adverse childhood experiences and delinquency and substance use in adolescence. J. Crim. Justice 2020, 66, 101637. [CrossRef]

29. Haahr-Pedersen, I.; Perera, C.; Hyland, P.; Vallières, F.; Murphy, D.; Hansen, M.; Spitz, P.; Hansen, P.; Cloitre, M. Females have more complex patterns of childhood adversity: Implications for mental, social, and emotional outcomes in adulthood. Eur. J. Psychotraumatol. 2020, 11, 1708618. [CrossRef]

30. Alcalá, H.E.; Tomiyama, A.J.; von Ehrenstein, O.S. Gender Differences in the Association between Adverse Childhood Experiences and Cancer. Women's Health Issues 2017, 27, 625-631. [CrossRef]

31. Richter, L.; Norris, S.; Pettifor, J.; Yach, D.; Cameron, N. Cohort Profile: Mandela's children: The 1990 birth to twenty study in South Africa. Int. J. Epidemiol. 2007, 36, 504-511. [CrossRef]

32. Richter, L.M.; Norris, S.A.; De Wet, T. Transition from Birth to Ten to Birth to Twenty: The South African cohort reaches 13 years of age. Paediatr. Périnat. Epidemiol. 2004, 18, 290-301. [CrossRef]

33. Yach, D.; Cameron, N.; Padayachee, N.; Wagstaff, L.; Richter, L.; Fonn, S. Birth to ten: Child health in South Africa in the 1990s. Rationale and methods of a birth cohort study. Paediatr. Périnat. Epidemiol. 1992, 5, 211-233. [CrossRef]

34. Yach, D.; Padayachee, G.N.; Cameron, N.; A Wagstaff, L.; Richter, L. 'Birth to Ten'-A study of children of the 1990's living in the Johannesburg-Soweto area. S. Afr. Med. J. 1990, 77, 325-326.

35. Schurer, S.; Trajkovski, K.; Hariharan, T. Understanding the mechanisms through which adverse childhood experiences affect lifetime economic outcomes. Labour Econ. 2019, 61, 101743. [CrossRef]

36. Hughes, K.; Ford, K.; Kadel, R.; Sharp, C.; Bellis, M. Health and financial burden of adverse childhood experiences in England and Wales: A combined primary data study of five surveys. BMJ Open 2020, 10, e036374. [CrossRef]

37. Vorster, J.; de Waal, L. Beneficiaries of the Child Support Grant: Findings from a National Survey. Soc. Work Pract.-Res. 2008, 20, 233-248.

38. Murray, C.J.L.; Vos, T.; Lozano, R.; Naghavi, M.; Flaxman, A.D.; Michaud, C.; Ezzati, M.; Shibuya, K.; Salomon, J.A.; Abdalla, S.; et al. Disability-adjusted life years (DALYs) for 291 diseases and injuries in 21 regions, 1990-2010: A systematic analysis for the Global Burden of Disease Study 2010. Lancet 2012, 380, 2197-2223. [CrossRef]

39. Mthembu, J.; Mabaso, M.; Khan, G.; Simbayi, L. Prevalence of psychological distress and its association with socio-demographic and HIV-risk factors in South Africa: Findings of the 2012 HIV prevalence, incidence and behaviour survey. SSM-Popul. Health 2017, 3, 658-662. [CrossRef]

40. van Duin, L.; Bevaart, F.; Zijlmans, J.; Luijks, M.A.; Doreleijers, T.A.H.; Wierdsma, A.I.; Oldehinkel, A.J.; Marhe, R.; Popma, A. The role of adverse childhood experiences and mental health care use in psychological dysfunction of male multi-problem young adults. Eur. Child Adolesc. Psychiatry 2019, 28, 1065-1078. [CrossRef]

41. Von Cheong, E.; Sinnott, C.; Dahly, D.; Kearney, P. Adverse childhood experiences (ACEs) and later-life depression: Perceived social support as a potential protective factor. BMJ Open 2017, 7, e013228. [CrossRef]

42. De Venter, M.; Demyttenaere, K.; Bruffaerts, R. The relationship between adverse childhood experiences and mental health in adulthood. A systematic literature review. Tijdschr. Voor Psychiatr. 2013, 55, 259-268.

43. Herzog, J.I.; Schmahl, C. Adverse Childhood Experiences and the Consequences on Neurobiological, Psychosocial, and Somatic Conditions Across the Lifespan. Front. Psychiatry 2018, 9, 420. [CrossRef]

44. Afifi, T.O.; Mather, A.; Boman, J.; Fleisher, W.; Enns, M.W.; MacMillan, H.; Sareen, J. Childhood adversity and personality disorders: Results from a nationally representative population-based study. J. Psychiatr. Res. 2011, 45, 814-822. [CrossRef] [PubMed]

45. Sheffler, J.L.; Stanley, I.; Sachs-Ericsson, N. Chapter 4-ACEs and Mental Health Outcomes. In Adverse Childhood Experiences: Using Evidence to Advance Research, Practice, Policy, and Prevention; Asmundson, G.J.G., Afifi, T.O., Eds.; Academic Press: Cambridge, MA, USA, 2020; pp. 47-69.

46. Wang, J.; Lloyd-Evans, B.; Giacco, D.; Forsyth, R.; Nebo, C.; Mann, F.; Johnson, S. Social isolation in mental health: A conceptual and methodological review. Soc. Psychiatry 2017, 52, 1451-1461. [CrossRef] [PubMed]

47. Lara, E.; Caballero, F.F.; Rico-Uribe, L.A.; Olaya, B.; Haro, J.M.; Ayuso-Mateos, J.L.; Miret, M. Are loneliness and social isolation associated with cognitive decline? Int. J. Geriatr. Psychiatry 2019, 34, 1613-1622. [CrossRef] [PubMed]

48. Holt-Lunstad, J.; Smith, T.B.; Baker, M.; Harris, T.; Stephenson, D. Loneliness and Social Isolation as Risk Factors for Mortality: A Meta-Analytic Review. Perspect. Psychol. Sci. 2015, 10, 227-237. [CrossRef]

49. Smith, K.J.; Gavey, S.; Riddell, N.E.; Kontari, P.; Victor, C. The association between loneliness, social isolation and inflammation A systematic review and meta-analysis. Neurosci. Biobehav. Rev. 2020, 112, 519-541. [CrossRef] [PubMed]

50. Brooks, S.K.; Webster, R.K.; Smith, L.E.; Woodland, L.; Wessely, S.; Greenberg, N.; Rubin, G.J. The psychological impact of quarantine and how to reduce it: Rapid review of the evidence. Lancet 2020, 395, 912-920. [CrossRef]

51. Republic of South Africa, South African Schools Act 1996. 2011. Available online: https://www.gov.za/sites/default/files/gcis_ document/201409/act84of1996.pdf (accessed on 3 December 2021).

52. Boyes, M.E.; Berg, V.; Cluver, L.D. Poverty moderates the association between gender and school dropout in South African adolescents. Vulnerable Child. Youth Stud. 2017, 12, 195-206. [CrossRef] 
53. Department of Basic Education, Republic of South Africa. Education Statistics in South Africa 2016; Department of Basic Education, Republic of South Africa: Pretoria, South Africa, 2016.

54. StatsSA. Education Series Volume III: Educational Enrolment and Achievement 2016; Statistics South Africa: Pretoria, South Africa, 2017.

55. Boden, J.; Horwood, L.; Fergusson, D.M. Exposure to childhood sexual and physical abuse and subsequent educational achievement outcomes. Child Abus. Negl. 2007, 31, 1101-1114. [CrossRef]

56. Wodarski, J.S.; Kurtz, P.D.; Gaudin, J.M.; Howing, P.T. Maltreatment and the School-Age Child: Major Academic, Socioemotional, and Adaptive Outcomes. Soc. Work 1990, 35, 506-513. [CrossRef]

57. Slade, E.P.; Wissow, L.S. The influence of childhood maltreatment on adolescents' academic performance. Econ. Educ. Rev. 2007, 26, 604-614. [CrossRef]

58. Leibbrandt, M.; Woolard, I.; Finn, A.; Argent, J. Trends in South African Income Distribution and Poverty since the Fall of Apartheid. In OECD Social, Employment and Migration Working Papers No. 101; OECD Publishing: Paris, France, 2010.

59. StatsSA. Quarterly Labour Force Survey (QLFS) Q2:2021; Statistics South Africa: Pretoria, South Africa, 2021.

60. Metzler, M.; Merrick, M.T.; Klevens, J.; Ports, K.A.; Ford, D.C. Adverse childhood experiences and life opportunities: Shifting the narrative. Child. Youth Serv. Rev. 2017, 72, 141-149. [CrossRef]

61. Sansone, R.A.; Leung, J.S.; Wiederman, M.W. Five forms of childhood trauma: Relationships with employment in adulthood Child Abus. Negl. 2012, 36, 676-679. [CrossRef] [PubMed]

62. Currie, J.; Widom, C.S. Long-Term Consequences of Child Abuse and Neglect on Adult Economic Well-Being. Child Maltreatment 2010, 15, 111-120. [CrossRef]

63. Covey, H.C.; Menard, S.; Franzese, R.J. Effects of Adolescent Physical Abuse, Exposure to Neighborhood Violence, and Witnessing Parental Violence on Adult Socioeconomic Status. Child Maltreatment 2013, 18, 85-97. [CrossRef] [PubMed]

64. World Economic Forum. The Global Competitiveness Report 2016-2017; World Economic Forum: Geneva, Switzerland, 2016.

65. StatsSA. Census 2011-Population Dynamics in South Africa; Report No. 03-01-67; Statistics South Africa: Pretoria, South Africa, 2015.

66. Redders, H. Regional Inequality and Rural Dependency in South Africa: How Can Opposing Trends in Regional Equality be Explained? SA-TIED Working Paper \#163; United Nations University World Institute for Development Economics Research SA-TIED: Helsinki, Finland, 2021.

67. Satumba, T.; Bayat, A.; Mohamed, S. The Impact of Social Grants on Poverty Reduction in South Africa. J. Econ. 2017, 8, 33-49. [CrossRef]

68. Aguero, J.M.; Carter, M.R.; Woolard, I. The Impact of Unconditional Cash Transfers on Nutrition: The South African Child Support Grant; Working Paper Number 06/08; SALDRU: Cape Town, South Africa, 2006.

69. Hajdu, F.; Granlund, S.; Neves, D.; Hochfeld, T.; Amuakwa-Mensah, F.; Sandström, E. Cash transfers for sustainable rural livelihoods? Examining the long-term productive effects of the Child Support Grant in South Africa. World Dev. Perspect. 2020, 19, 100227. [CrossRef]

70. South African Child Gauge: Children and Social Assistance; Delany, A., Jehoma, S., Lake, L., Eds.; Children's Institute, University of Cape Town: Cape Town, South Africa, 2016.

71. Patel, L.; Knijn, T.; Gorman-Smith, D.; Hochfeld, T.; Isserow, M.; Garthe, R.; Chiba, J.; Moodley, J.; Kgaphola, I. Family Contexts, Child Support Grants and Child Well-Being in South Africa: Summary Report; The Programme to Support Pro-poor Policy Development (PSPPD); Department of Planning, Monitoring and Evaluation (DPME): Pretoria, South Africa, 2017.

72. Stats, S.A. Mid-Year Population Esitmates; Statistics South Africa: Pretoria, South Africa, 2021.

73. Shamu, S.; Shamu, P.; Zarowsky, C.; Temmerman, M.; Shefer, T.; Abrahams, N. Does a history of sexual and physical childhood abuse contribute to HIV infection risk in adulthood? A study among post-natal women in Harare, Zimbabwe. PLoS ONE 2019, 14, e0198866. [CrossRef]

74. Dunkle, K.L.; Decker, M. Gender-Based Violence and HIV: Reviewing the Evidence for Links and Causal Pathways in the General Population and High-risk Groups. Am. J. Reprod. Immunol. 2012, 69, 20-26. [CrossRef]

75. Jewkes, R.; Dunkle, K.; Nduna, M.; Levin, J.; Jama, N.; Khuzwayo, N.; Koss, M.; Puren, A.; Duvvury, N. Factors associated with HIV sero-status in young rural South African women: Connections between intimate partner violence and HIV. Int. J. Epidemiol. 2006, 35, 1461-1468. [CrossRef]

76. Gibbs, A.; Dunkle, K.; Washington, L.; Willan, S.; Shai, N.; Jewkes, R. Childhood traumas as a risk factor for HIV-risk behaviours amongst young women and men living in urban informal settlements in South Africa: A cross-sectional study. PLoS ONE 2018, 13, e0195369. [CrossRef] [PubMed]

77. $\mathrm{Wu}, \mathrm{L} .-\mathrm{T}$. Substance abuse and rehabilitation: Responding to the global burden of diseases attributable to substance abuse. Subst. Abus. Rehabil. 2010, 1, 5-11. [CrossRef]

78. Gibbs, A.; Jewkes, R.; Willan, S.; Washington, L. Associations between poverty, mental health and substance use, gender power, and intimate partner violence amongst young (18-30) women and men in urban informal settlements in South Africa: A cross-sectional study and structural equation model. PLoS ONE 2018, 13, e0204956. [CrossRef] [PubMed]

79. Mersky, J.; Topitzes, J.; Reynolds, A. Impacts of adverse childhood experiences on health, mental health, and substance use in early adulthood: A cohort study of an urban, minority sample in the U.S. Child Abus. Negl. 2013, 37, 917-925. [CrossRef]

80. Currie, J.; Tekin, E. Understanding the Cycle: Childhood Maltreatment and Future Crime. J. Hum. Resour. 2012, 47, 509-549. [CrossRef] [PubMed]

81. Lanctôt, N.; Le Blanc, M. Explaining Deviance by Adolescent Females. Crime Justice 2002, 29, 113-202. [CrossRef] 
82. Rivera, B.; Widom, C.S. Childhood Victimization and Violent Offending. Violence Vict. 1990, 5, 19-35. [CrossRef]

83. Maxfield, M.G.; Widom, C.S. The cycle of violence. Revisited 6 years later. Arch. Pediatr. Adolesc. Med. 1996, 150, 390-395. [CrossRef]

84. Dawkins, M.P. Drug use and violent crime among adolescents. Adolescence 1997, 32, 395-405.

85. Lipsey, M.W.; Derzon, J.H. Predictors of Violent or Serious Delinquency in Adolescence and Early Adulthood: A Synthesis of Longitudinal Research; SAGE Publications: Thousand Oaks, CA, USA, 1998; pp. 86-105.

86. Craig, J.M.; Intravia, J.; Wolff, K.T.; Baglivio, M.T. What Can Help? Examining Levels of Substance (Non)use as a Protective Factor in the Effect of ACEs on Crime. Youth Violence Juv. Justice 2019, 17, 42-61. [CrossRef]

87. LeMasters, K.; Bates, L.M.; Chung, E.O.; Gallis, J.A.; Hagaman, A.; Scherer, E.; Sikander, S.; Staley, B.S.; Zalla, L.C.; Zivich, P.N.; et al. Adverse childhood experiences and depression among women in rural Pakistan. BMC Public Health 2021, $21,1-11$. [CrossRef] [PubMed]

88. Escueta, M.; Whetten, K.; Ostermann, J.; O'Donnell, K. Adverse childhood experiences, psychosocial well-being and cognitive development among orphans and abandoned children in five low income countries. BMC Int. Health Hum. Rights 2014, 14, 6. [CrossRef] [PubMed]

89. Ramaiya, A.; Choiriyyah, I.; Heise, L.; Pulerwitz, J.; Blum, R.W.; Levtov, R.; Lundgren, R.; Richardson, L.; Moreau, C. Understanding the Relationship Between Adverse Childhood Experiences, Peer-Violence Perpetration, and Gender Norms Among Very Young Adolescents in Indonesia: A Cross-Sectional Study. J. Adolesc. Health 2021, 69, S56-S63. [CrossRef] [PubMed]

90. Kane, J.B.; Harris, K.M.; Morgan, S.P.; Guilkey, D.K. Pathways of Health and Human Capital from Adolescence into Young Adulthood. Soc. Forces 2017, 96, 949-976. [CrossRef]

91. Anda, R.F.; Butchart, A.; Felitti, V.J.; Brown, D.W. Building a Framework for Global Surveillance of the Public Health Implications of Adverse Childhood Experiences. Am. J. Prev. Med. 2010, 39, 93-98. [CrossRef]

92. Gilbert, R.; Widom, C.S.; Browne, K.; Fergusson, D.; Webb, E.; Janson, S. Burden and consequences of child maltreatment in high-income countries. Lancet 2009, 373, 68-81. [CrossRef]

93. Evans, G.W.; Kim, P. Multiple risk exposure as a potential explanatory mechanism for the socioeconomic status-health gradient. Ann. N. Y. Acad. Sci. 2010, 1186, 174-189. [CrossRef] 